\title{
Morphology of heart valves preserved by liquid nitrogen freezing
}

\author{
LC ARMIGER, RW THOMSON, MG STRICKETT, BG BARRATT-BOYES \\ From the Department of Pathology, University of Auckland School of Medicine, Auckland, and the \\ Cardiothoracic Surgical Unit, Green Lane Hospital, Auckland, New Zealand
}

\begin{abstract}
As a preliminary to establishing a frozen valve bank for replacement surgery, the possible effects of the proposed freezing and thawing procedure on tissue structure were assessed in 16 human pulmonary valves removed from cadavers at necropsy and nine dog valves obtained fresh. The valves were frozen and stored in liquid nitrogen for intervals ranging from 23 to 380 days. Blocks of tissue cut from the central area of one leaflet, and including some adjacent arterial wall and ventricular myocardium, were obtained both before freezing and after thawing and examined by a large specimen resin embedding technique for light and electron microscopy, with histochemical staining for matrix material. Control and thawed tissue from all valves appeared similar, indicating good preservation irrespective of storage time. Fine structural alterations in the cellular elements correlated with the total interval of autolysis (from death to freezing) rather than the cause of death or other variables and were not uniform in any of the specimens.
\end{abstract}

The demand for valve replacement surgery at Green Lane Hospital is currently so great that an adequate supply of human valves for grafting is difficult to maintain with the wet storage method at present in routine use (immersion in antibiotic containing Hanks's solution at $4^{\circ} \mathrm{C}$ ). ${ }^{\prime}$ Valves are discarded if they have not been used within three months of collection because of possible loss of soluble components from the connective tissue, a process that might lead to weakening of the leaflets or an altered host response after implantation. Freezing of valves in liquid nitrogen, after suitable sterility testing or sterilisation procedures, or both, would allow their indefinite storage and eliminate wastage. As part of a preliminary evaluation of the techniques required for establishing a frozen valve bank, we have recently assessed the structural preservation of human and dog valves after freezing and thawing, using a large specimen resin embedding technique to enable combined light and electron microscopic examination of the valve leaflet and supporting tissues.

Address for reprint requests: Dr LC Armiger, Department of Pathology, School of Medicine, University of Auckland, Private Bag, Auckland, New Zealand.

Accepted 5 March 1985

\section{Methods}

Sixteen human pulmonary valves (table) were obtained at necropsy from donors comprising 11 males and four females aged 15-53 years, who had died from various causes. The time intervals between death and procurement of the valves for freezing ranged from seven to 36 hours.

A further nine valves, both pulmonary and aortic, were obtained fresh from dogs used for short term experimental cardiac surgery and were frozen within two to three hours of collection.

The freezing technique was based on that used routinely in the department of cardiac surgery of the Prince Charles Hospital, Chermside, Queensland, Australia. Each valve was sealed into an individual plastic bag containing $20 \mathrm{ml}$ of $10 \%$ dimethyl sulphoxide in TC 199 medium, and the bag was insulated in such a manner as to produce a cooling rate of about $1.5^{\circ} \mathrm{C}$ a minute after it had been placed in a liquid nitrogen freezer. Valves were stored in a vapour phase of liquid nitrogen (boiling point $-196^{\circ} \mathrm{C}$ ) and thawed rapidly by immersion of the bag in water at $40^{\circ} \mathrm{C}$ for two minutes, with subsequent rinsing in Hanks's solution.

In this study both human and dog valves were stored for periods ranging from 23 to 380 days before being thawed.

Both before freezing and after thawing a block 
3-4 mm wide, including not only leaflet tissue but also some supporting arterial wall and adjacent myocardium, was removed from the central area of one of the cusps of each valve (fig 1). These blocks were subdivided into three or four blocks $1 \mathrm{~mm}$ thick and the tissue was fixed in phosphate buffered $2.5 \%$ glutaraldehyde ( $\mathrm{pH} 7.2-7.4$ ) for 18-24 hours. It was then washed in $0.1 \mathrm{~mol} / 1$ phosphate buffer, postfixed in $1 \%$ osmium tetroxide, dehydrated in graded ethanols, and embedded in epoxy resin in JB4 moulds $(12 \times 6 \mathrm{~mm})$. Additional blocks from each valve were embedded in paraffin wax for histochemical examination.
The resin embedded material was initially sectioned for light microscopy at $1-2 \mu \mathrm{m}$ on a Sorvall JB4 microtome. These sections were mounted on glass slides and stained with toluidine blue ${ }^{2}$ or by the Azan technique ${ }^{3}$ after removal of the resin and bleaching of the osmium tetroxide. Subsequently selected areas were trimmed down by the mesa method and sectioned with diamond knives at 50 $100 \mathrm{~nm}$ for electron microscopy. The ultrathin sections were mounted on plain copper grids, stained with uranyl acetate and lead citrate, and examined in a Philips EM300 electron microscope at an accelerating voltage of $60 \mathrm{Kv}$. The paraffin wax

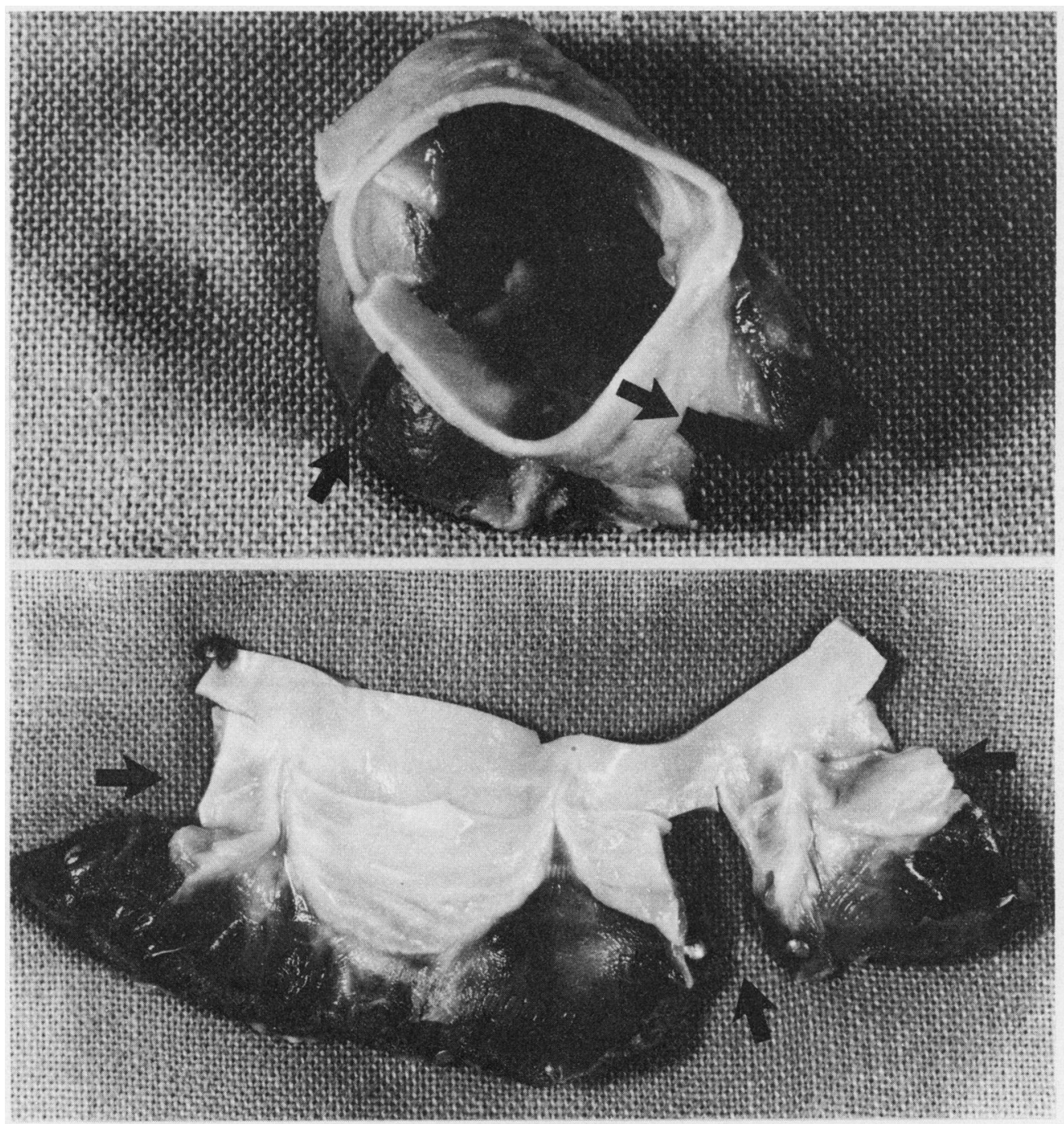

Fig 1 Valves displayed to show method of sampling for morphological examination. Arrows indicate the location of blocks removed. (a) As seen from above $(\times 2)$. (b) As seen in opened out specimen $(\times 1)$. 


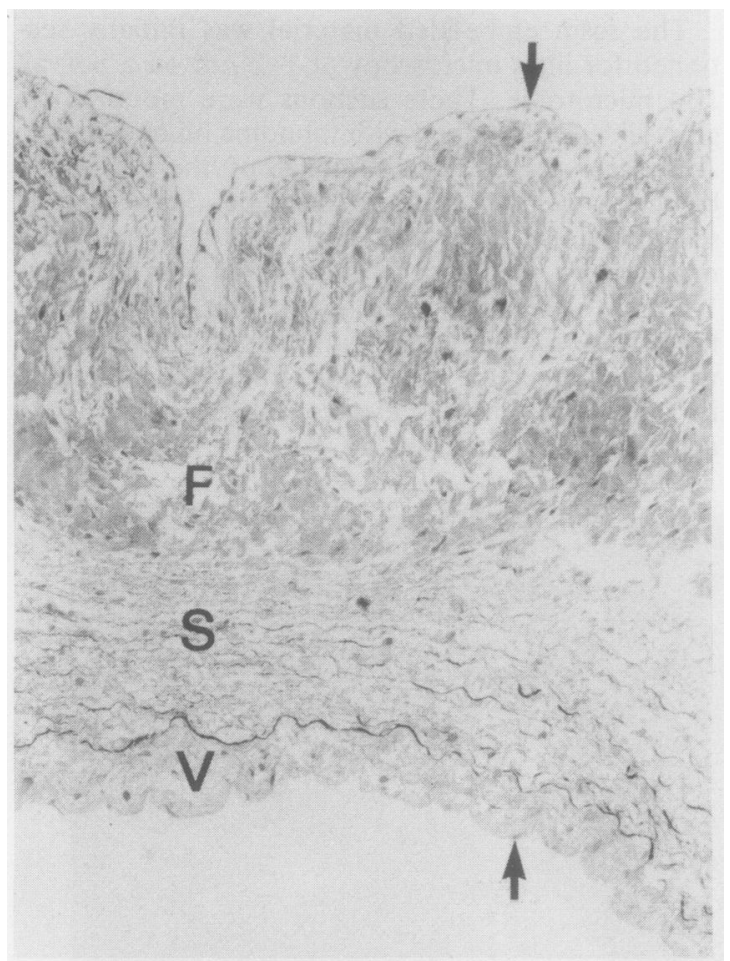

Fig 2 Light micrograph of $1 \mu \mathrm{m}$ thick resin section of a canine aortic valve showing densely collagenous fibrosa $(F)$ with strongly folded surface, loosely organised spongiosa $(S)$ with elastic fibres and small collagen bundles, thin collagenous ventricularis $(V)$, and intact endothelium on both surfaces (arrows). Cells are scattered at random throughout all three layers. $(\times 37$. $)$

embedded material was sectioned at $6 \mu \mathrm{m}$ and stained by the Alcian blue technique, ${ }^{4}$ a Van Giesen counterstain being used.

\section{Results}

The quality of the light microscopic sections prepared from the large resin embedded specimens was superior to that of conventional histological preparations in that much finer detail was apparent. Both the quality of sections and the typical structure of semilunar valves ${ }^{5}$ are illustrated in figure 2 , which shows a sectioned dog aortic valve leaflet after freezing and thawing. Structural differences between the control and the frozen and thawed specimens were not detectable in either the human or the dog series of valves, irrespective of duration of storage or other variables. In all cases the architecture of the leaflet was well preserved after storage (fig 2 ) and both collagenous and elastic elements retained their characteristic appearance. Elastic fibres were relatively electron lucent and surrounded by a more electron dense halo of finely filamentous proelastin (fig 3 ). Collagen fibres were essentially isodiametric (figs 3 and 4) and showed typical banding with a regular periodicity (fig 4). No degenerative changes were observed in individual fibres or bundles.

By electron microscopy the matrix or ground substance of the valve leaflet connective tissue showed a delicate network of spicules and filaments typical of acid mucopolysaccharide material (fig 4). Although some variation in the density of this material was observed from one valve to another and also within any one section examined, no readily detectable differences between the control and the frozen and thawed specimens of each valve were apparent. Similarly, the characteristic bluish green acid mucopolysaccharide reaction in the alcian blue stained paraffin sections was concentrated predominantly in the spongiosa in each section of leaflet and varied in intensity from valve to valve, but no differences between the control and the frozen and thawed specimens could be detected.

In the dog valves, both before and after storage,

Data on the human pulmonary valves

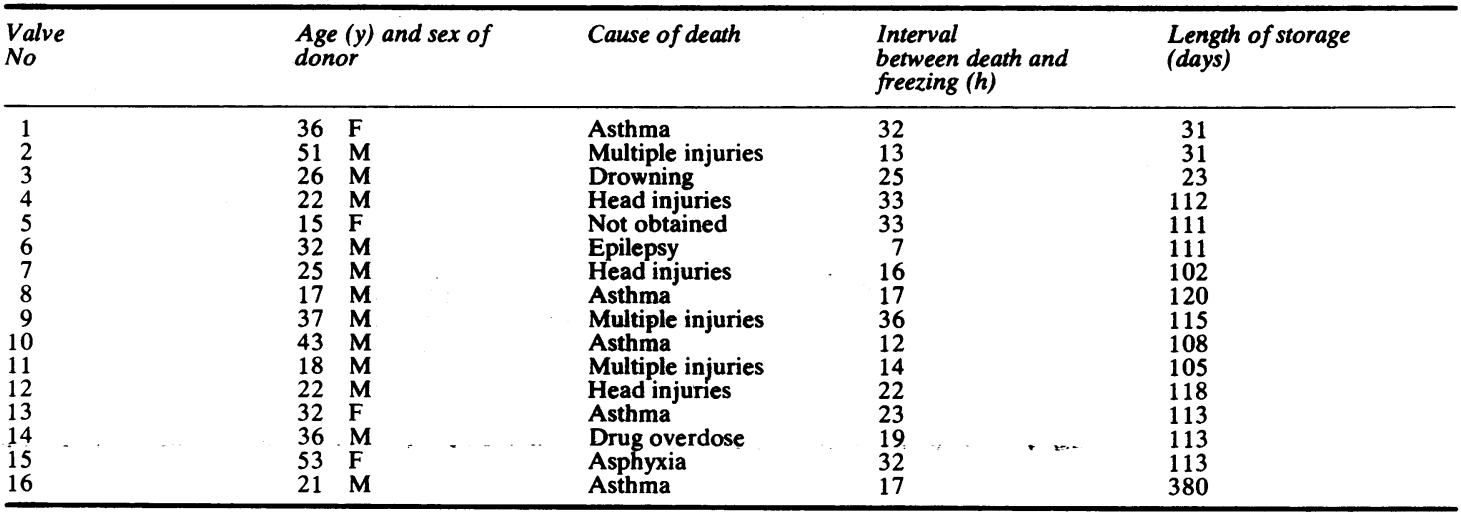


most intracuspal cells presented a largely normal fine structural appearance except for mild or moderate clumping of the nuclear chromatin, focal dilatation of the endoplasmic reticulum, and some cell to cell variation in electron density of the cytoplasm. Occasional cells showed also a slight swelling of the mitochondria, the presence of single lipid droplets, or focal membrane degenerations such as myelin figures (fig 5).

The fine structure of the cells in the human valves was more variable and ranged from near normal, as described for the canine material, through degenerating or senescent (with many lipid droplets, generalised swelling of organelles, and breaks in the plasma membrane) to frankly necrotic (with total absence of plasma membrane and grossly swollen, disintegrating organelles)-see figs 3 and 6 . Cells showing degenerative changes were distributed at random throughout all three layers of the leaflet and severely altered or necrotic ones often lay beside those showing little alteration from the normal. But, the relative proportions of altered and nearly normal cells observed varied from valve to valve and appeared to be related to the interval between death and freezing (table), most cells having a nearly normal appearance in the valves frozen less than 18 hours after death of the donor and progressively more degenerating and necrotic cells being seen in those frozen after longer periods of postmortem autolysis. As in the canine material, control and frozen and thawed specimens from each valve did not appear significantly different.

The endothelial covering of the leaflets was intact in all dog specimens (figs 2 and 7) but partially or completely lacking in the human specimens. Where persistent endothelial remnants were seen in sections of human leaflets the cells usually had a degenerate appearance (fig 8).

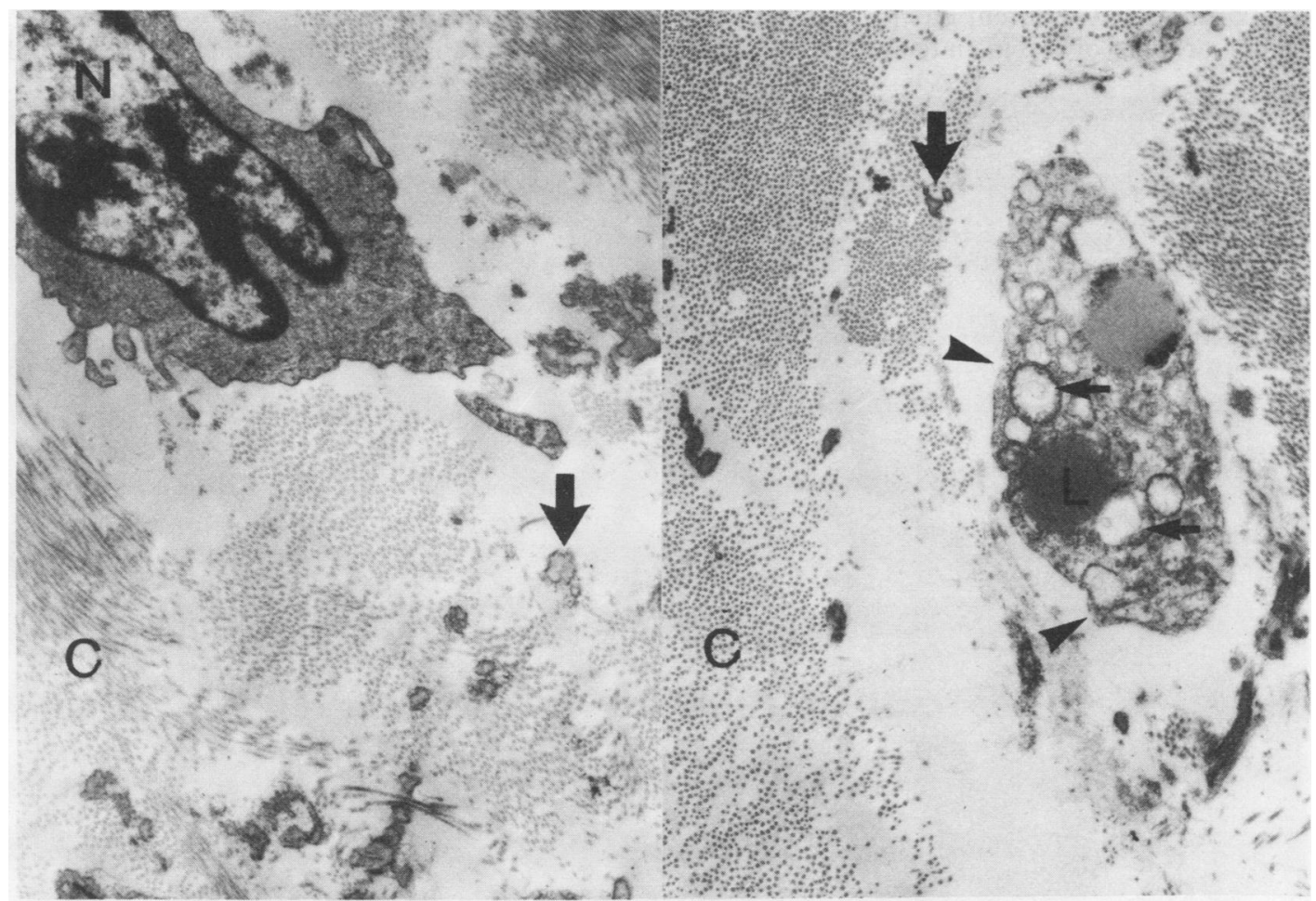

Fig 3 Electron micrographs taken from the same area of a human pulmonary valve (No 2) after freezing and thawing, showing elastic fibres (arrows), collagen (C) cut in various orientations, and two cells, one of which (left) is of normal appearance except for moderate clumping of the nuclear chromatin $(N)$, while the other (right) shows swollen mitochondria (small arrows), lipid droplets $(L)$, and breaks in the plasma membrane (arrowheads). $(\times$ 11 900.) 


\section{Discussion}

In the search for better methods of storing cardiac valves for replacement surgery, cryopreservation is an obvious and attractive possibility. Liquid nitrogen freezing techniques have already met with widespread success in biology and medicine as a means of long term storage for cells and tissues. The use of cryoprotectants such as glycerol and dimethyl sulphoxide to prevent ice crystal formation, with carefully controlled rates of freezing and thawing, allows both structure and viability to be retained almost indefinitely. Cryopreservation of heart valves has, however, already been used in some cardiac surgery units ${ }^{6-8}$ for some years and has not altogether fulfilled its promise. At the British National Heart Hospital, for example, it has been found that, while the performance of frozen valves parallels that of fresh ones during the first five years after implantation, there is subsequently a greater tendency for the frozen valves to undergo degenerative changes leading to failure. ${ }^{9}$

The clinical success of cardiac valve grafts has been correlated by different groups of investigators with one or other of two main features of the donor

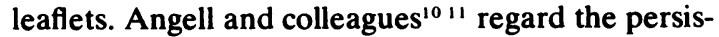
tence of viable fibroblasts as being of paramount importance, whereas Barratt-Boyes and associates $^{12-14}$ consider that retention of the acid mucopolysaccharide rich ground substance binding together the structural elements of the connective tissue is more likely to be essential for graft survival. Clearly, both these features should be assessed in the evaluation of potential storage methods for grafts.

Our results indicate that the freezing technique studied does not affect either the condition of the intracuspal fibroblasts or the distribution of the matrix material of valve leaflet connective tissue. Fibroblast viability has usually been determined by culture methods, ${ }^{6}$ but this approach suffers from the obvious drawback that it is non-quantitative and does not indicate either inhomogeneity in a cell population or the distribution pattern of viable cells within the tissue examined. Autoradiographic techniques have been tried in an attempt to circumvent these difficulties, ${ }^{1516}$ but they are relatively complex and time consuming and have found little favour as routine testing procedures.

While there is probably no single ideal method of

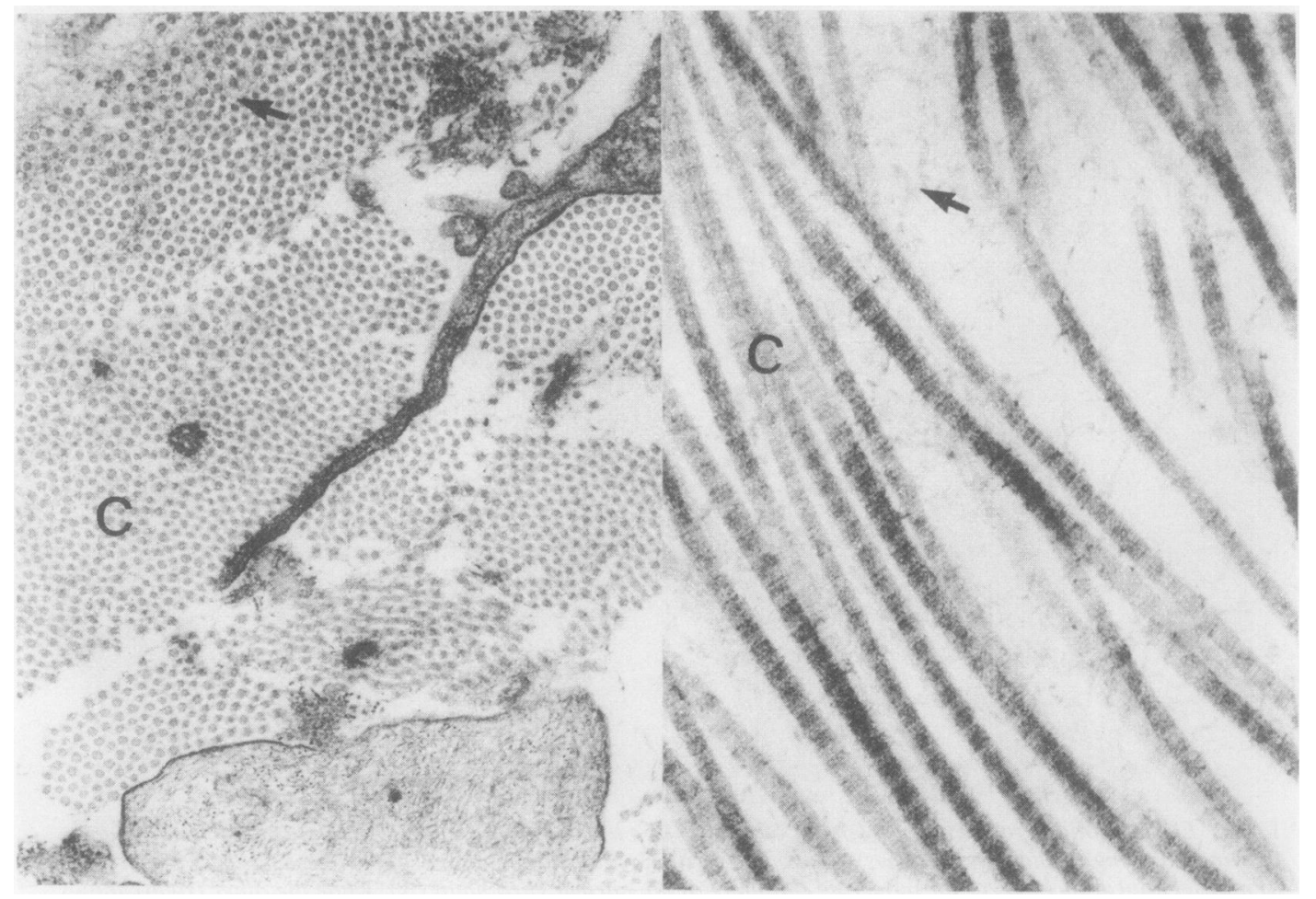

Fig 4 Electron micrographs taken from control (left) and frozen and thawed (right) specimens of the same human pulmonary valve (No 8) showing collagen fibres (C) and matrix material (arrows) lying between them. (Left, $\times 24250$; right, $\times 60650$. 
examining this aspect of valve condition, changes in fine structure reflect quite closely the biological condition of cells and can be used conveniently to distinguish viable from non-viable fibroblasts in leaflet specimens. ${ }^{14} 17$ The morphological approach does allow relative numbers and overall distribution of viable cells to be estimated also. Our observations on both human and canine material are consistent with a previous report ${ }^{17}$ that the cell populations in valve leaflets collected for grafting are usually not uniform morphologically. We observed a range of appearances from normal to necrotic in all human material irrespective of the origin, circumstances of collection, and subsequent treatment of valves. Thus we must assume that there is a normal turnover of fibroblasts in the cusps of semilunar valves, just as there is in most other tissues, and that adverse conditions such as postmortem autolysis and storage procedures will probably alter the balance of viable, senescent, and necrotic cells progressively over a critical time interval rather than produce a rapid and clearcut transition from all viable to all non-viable. This emphasises the importance of using more than a single "presence or absence" method of demon- strating viable fibroblasts if it becomes established unequivocally that viability is a crucial factor for valve survival.

The experimental studies of McGregor and colleagues, however, using tissue culture with assessment of protein and collagen synthesis on both stored and implanted material, ${ }^{18-20}$ have cast serious doubt on the viability theory. Reservations about the persistence of cellular viability in cryopreserved valves in particular have been expressed by Rajotte and colleagues, ${ }^{21}$ who carried out a very detailed histological examination of semilunar valves cultured after freezing and thawing; and Angell and colleagues have admitted ${ }^{22}$ that methods more sophisticated than those used originally have shown half the fibroblasts in their cryogenically stored grafts to be incapable of division.

Assessment of the condition of the ground substance or matrix of the connective tissue presents an even more difficult problem. Electron microscopic examination and histochemical staining for acid mucopolysaccharides, as used in our study, are not quantitative methods and allow only relatively gross comparisons to be made. Although we observed

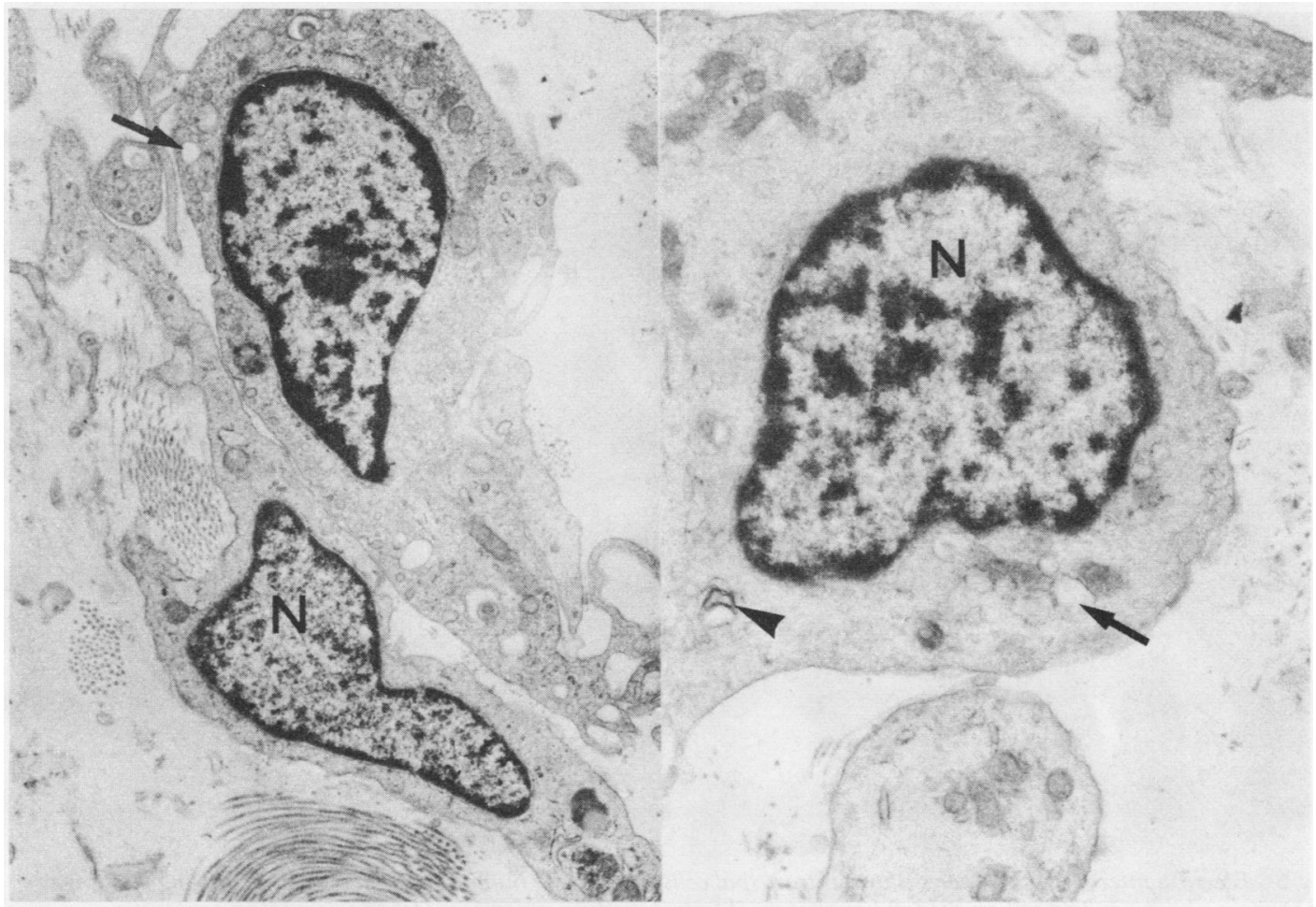

Fig 5 Electron micrographs of intracuspal cells in canine aortic leaflets, showing only moderate clumping of chromatin in the nuclei $(N)$, focal dilatation of endoplasmic reticulum (arrows), and a myelin figure (arrowhead). (Left, $\times 10$ 250; right, $\times 21$ 950.) 
good general preservation of the matrix material after freezing and thawing, acid mucopolysaccharides are known to be able to diffuse readily out of tissues held in aqueous solutions, ${ }^{5}$ and small losses (such as our methods would not indicate) may have occurred during the preparation and thawing phases and may be critical in valves used for replacement surgery. These substances have also been found to decrease with advancing age in human valves ${ }^{23}$; hence more consideration may need to be given to age of donors. Further work on the importance of the matrix in valve graft connective tissue is undoubtedly required and this should include the development of microchemical methods for analysis of matrical components. Freezing of valves, however, rather than their long term storage in fluids, certainly limits the loss of acid mucopolysaccharides and other constituents of the ground substance.

Histopathological studies carried out in our laboratory on both human and canine valve grafts $^{24-26}$ have shown that the endothelium covering both surfaces of the leaflets does not long persist after grafting. Endothelium generally seems likely to be readily lost from underlying tissues, particularly in response to anoxia, ${ }^{27}$ which would occur during autolysis of valves removed from cadavers as well as during handling. ${ }^{5}$ The persistence of the endothelium in all frozen and thawed canine specimens was therefore a little surprising. As anticipated, however, loss of endothelial cells was more widespread in the human series than in the fresher dog valves. Since loss of endothelium exposes the underlying connective tissue to surrounding fluid in vitro or to circulating blood in vivo and may be expected to promote leaching out of matrix material, this aspect of valve graft biology deserves more attention.

In summary, using morphological methods of assessment, we have shown that liquid nitrogen

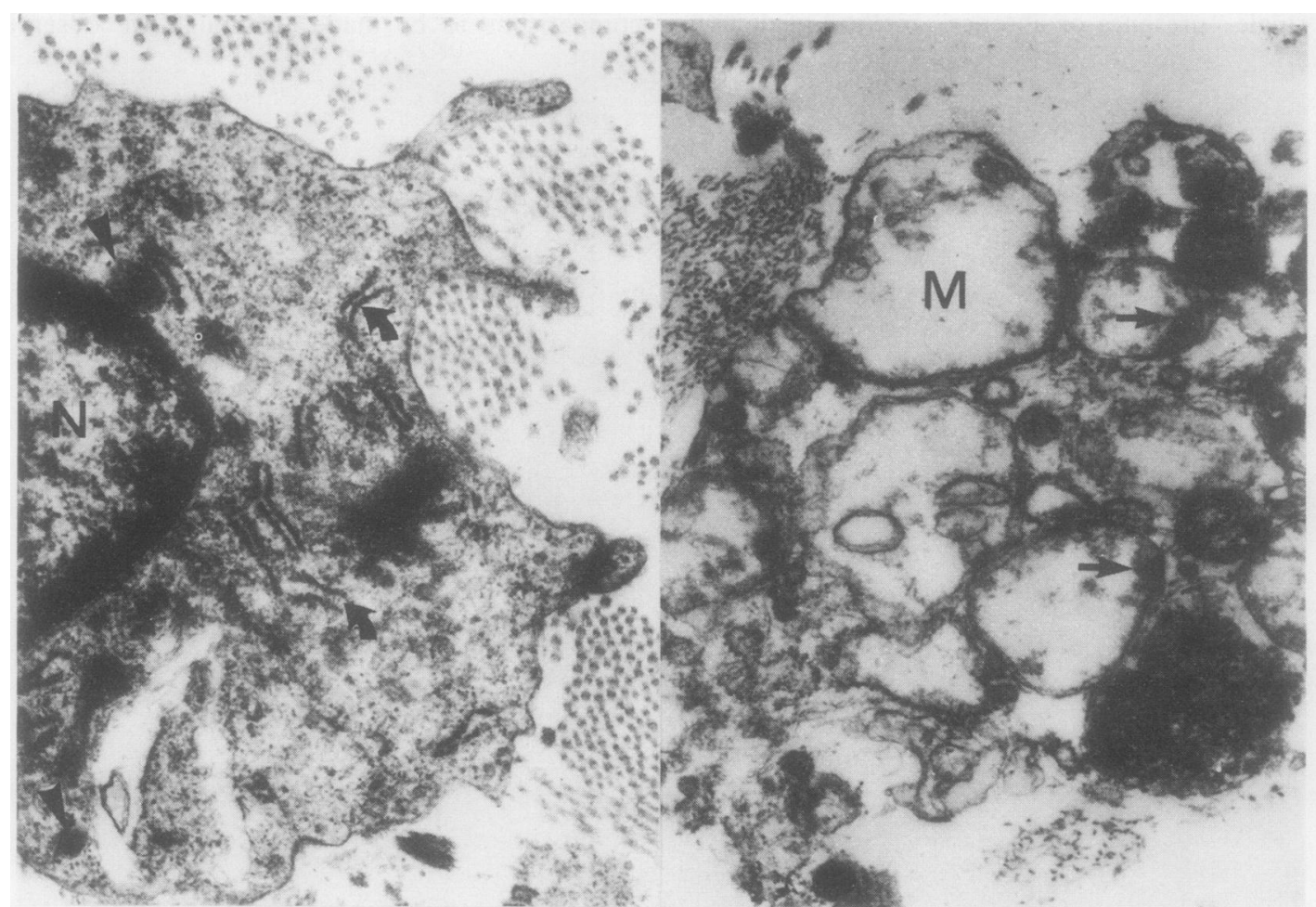

Fig 6 Electron micrographs of parts of two intracuspal cells in the same human pulmonary valve showing the range of changes observed. The cell on the left has slightly clumped nuclear chromatin $(N)$ but normal endoplasmic reticulum (curved arrows) and mitochondria (arrowheads) and an intact plasma membrane. The cell on the right is devoid of plasma membrane and has grossly swollen mitochondria $(M)$, apparently without cristae but often with large, dense inclusions (arrows), and disintegrating cytoplasmic contents. (Left and right, $\times 23$ 350.) 


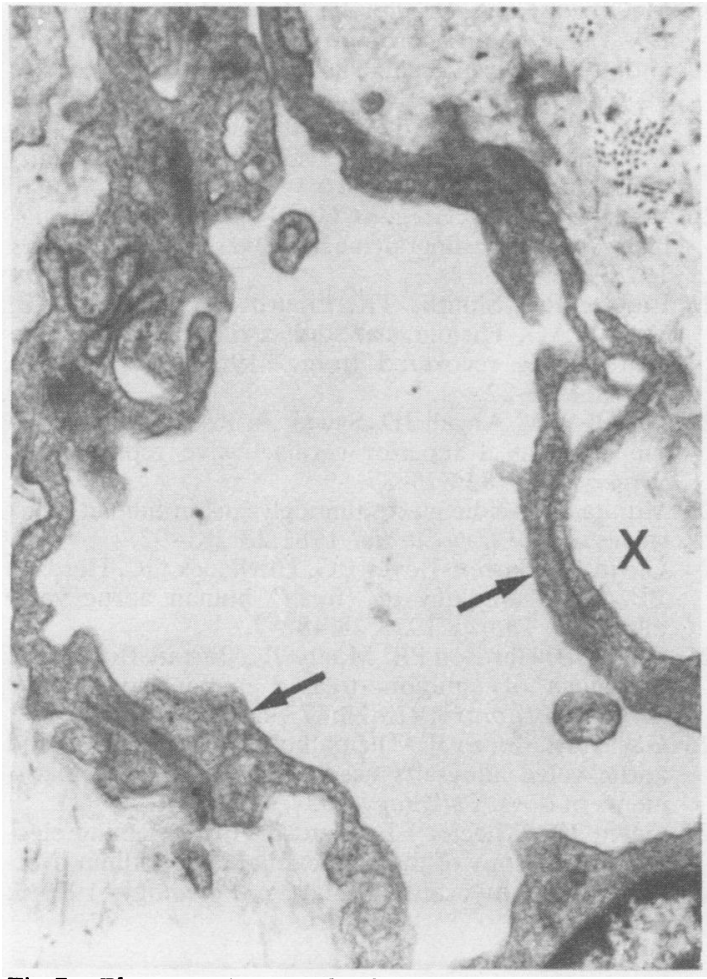

Fig 7 Electron micrograph of part of the endothelial covering (arrows) of a canine aortic valve showing normal cell structure and one focus of incipient detachment $(X)$. $(\times 12150$.

freezing of cardiac semilunar valves, with dimethyl sulphoxide as the cryoprotectant, and thawing after storage periods of up to 380 days, does not result in demonstrable change in any component of the leaflet tissue. Although the possibility of subtle alterations, such as loss of some readily diffusible molecules from the matrix or conformational changes in structural proteins, cannot be ruled out, this preservation technique appears superior to storage in fluids and of greater potential for the development of valve banks. Experiments are in progress to test the performance of frozen valve leaflets in vivo, since the clinical experience of other groups warrants some degree of caution.

We are grateful for the technical assistance of Sallyann Fitzgerald, Judith Wilson, Laurel McCulloch, Lynne Logan, and Philip Whiting. The study was supported by grants from the Medical Research Council of New Zealand and the National Heart Foundation of New Zealand.

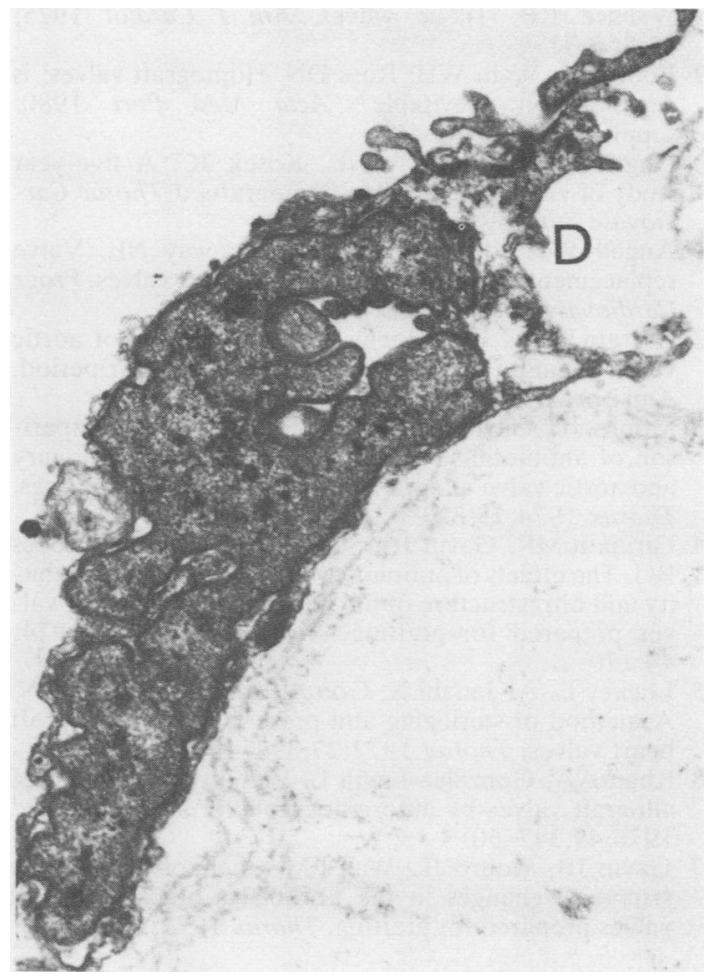

Fig 8 Electron micrograph of an endothelial remnant on a human pulmonary valve showing a disintegrating cell $(D)$ adjoining another cell of normal structure but irregular contours. $(\times 14$ 000.)

\section{References}

1 Barratt-Boyes BG, Roche AHG, Whitlock RML. Six year review of the results of freehand aortic valve replacement using an antibiotic sterilized homograft valve. Circulation 1977; 55:353-61.

2 Richardson KC, Jarrett L, Finke EH. Embedding in epoxy resins for ultrathin sectioning in electron microscopy. Stain Techn 1960;35:313-23.

3 Mallory FB. Pathological technique. New York: Hafner Publishing Co, 1961:154-5.

4 Disbrey BD, Rack JH. Histological laboratory methods. Edinburgh: E and S Livingstone, 1970:1456.

5 Ferrans VJ, Spray TL, Billingham ME, Roberts WC. Structural changes in glutaraldehyde-treated porcine heterografts used as substitute cardiac valves. Transmission and scanning electron microscopic observations in 12 patients. Am J Cardiol 1978;41:1159-84.

6 Angell JD, Christopher BS, Hawtrey O, Angell WM. A fresh, viable human heart valve bank: Sterilization, sterility testing, and cryogenic preservation. Transplant Proc 1976;8, suppl 1:139-47.

7 Ross DN. Biological tissue in heart valve replacement. J Jap Associ Thorac Surg 1973;21:555-61. 
8 Wallace RB. Tissue valves. Am J Cardiol 1975; 35:866-71.

9 Bodnar E, Wain WH, Ross DN. Homograft valves: is degeneration inevitable? Acta Med Port 1980; suppl: 147-53.

10 Angell WW, Shumway NE, Kosek JC. A five-year study of viable aortic valve homografts. $J$ Thorac Cardiovasc Surg 1972;64:329-39.

11 Angell WW, de Lanerolle P, Shumway NE. Valve replacement: present status of homograft valves. Progr Cardiovasc Dis 1973;15:589-622.

12 Barratt-Boyes BG, Roche AHG. A review of aortic valve homografts over a six and one-half year period. Ann Surg 1969;170:483-90.

13 Monro JL, Gavin JB, Barratt-Boyes BG. A comparison of antibiotic-sterilized, stent-mounted pulmonary and aortic valve allografts in the mitral region of dogs. Thorax 1974;29:323-8.

14 Girinath MR, Gavin JB, Strickett MG, Barratt-Boyes BG. The effects of antibiotics and storage on the viability and ultrastructure of fibroblasts in canine heart valves prepared for grafting. Aust $N Z J$ Surg 1974; 44:170-2.

15 Lockey E, Al-Janabi N, Gonzalez-Lavin L, Ross DN. A method of sterilizing and preserving fresh allograft heart valves. Thorax 1972;27:398-400.

16 Khan AA, Gonzalez-Lavin L. Viability assessment of allograft valves by autoradiography. Yale J Biol Med 1976;49:347-50.

17 Gavin JB, Monro JL, Wall FM, Chalcroft SWC. Fine structural changes in the fibroblasts of canine heart valves prepared for grafting. Thorax 1973;28:748-55.
18 McGregor CGA, Bradley JF, McGee J O' D, Wheatley DJ. Tissue culture, protein and collagen synthesis in antibiotic sterilized canine heart valves. Cardiovasc Res 1976; 10:389-93.

19 McGregor CGA, Bradley JF, McGee J O' D, Wheatley DJ. Viability in human heart valves prepared for grafting. Cardiovasc Res 1976;10:394-7.

20 Wheatley DJ, McGregor CGA. Post implantation viability in canine allograft heart valves. Cardiovasc Res 1977;11:78-85.

21 Rajotte RV, Shnitka TK, Liburd EM, Dossetor JB, Voss WAG. Histological studies on cultured canine heart valves recovered from $-196^{\circ} \mathrm{C}$. Cryobiology $1977 ; 14: 15-22$.

22 Angell WW, Angell JD, Sywak A, Kosek JC. The tissue valve as a superior cardiac valve replacement. Surgery 1977;82:875-87.

23 Murata K, Acidic glycosaminoglycans in human heart valves. J Mol Cell Cardiol 1981;13:281-92.

24 Gavin JB, Barrett-Boyes BG, Hitchcock GC, Herdson PB. Histopathology of "fresh" human aortic valve allografts. Thorax 1973;28:482-7.

25 Gavin JB, Herdson PB, Monro JL, Barratt-Boyes BG. Pathology of antibiotic-treated human heart valve allografts. Thorax 1973;28:473-81.

26 Gavin JB, Monro JL. The pathology of pulmonary and aortic valve allografts used as mitral valve replacements in dogs. Pathology 1974;6:119-27.

27 Gavin JB, Wheeler EE, Herdson PB. Scanning electron microscopy of the endocardial endothelium overlying early myocardial infarcts. Pathology 1973;5: 45-8. 